\title{
Trying Harder and Doing Worse: HOW GROCERY SHOPPERS TRACK IN-STORE SPENDING
}

\section{Shopping on a Budget}

All over the world the economic crisis has raised the number of households which are below the poverty line. A careful tracking of expenditures has become increasingly necessary to avoid financial distress. Models of spending behavior often implicitly assume that budget shoppers know how much they spend while shopping. As demonstrated here, this assumption is the exception rather than the rule.

\section{How Shoppers Actually Keep Track of In-Store Spending}

Two field studies and two laboratory shopping simulations offer new insights on strategies used to keep track of spending and their consequences. The number one reason for trying to keep track of the spending is clearly a constrained budget. Most shoppers use computational estimation strategies. Those who aim to be particularly accurate in their estimations either use calculators or try to calculate exact numbers. The computational strategies include (1) rounding prices down, (2) rounding prices up, (3) rounding prices to close denominations, (4) combining compatible prices, and (5) multiplying a central price. In the field survey, rounding prices up proved to be the dominant strategy for estimating the total prices (the grocery shopping baskets of the participants contained the very common dominant price endings from $\$ .51-$ .99). In the experiments the endings were manipulated according to four different conditions (traditional from $\$ .51$ to $\$ .99$, price endings ranging from $\$ .01$ to $\$ .49$, the full range of price endings from $\$ .01$ to $\$ .99$ and compatible numbers such as $\$ .02$ and $\$ .98)$. Participants

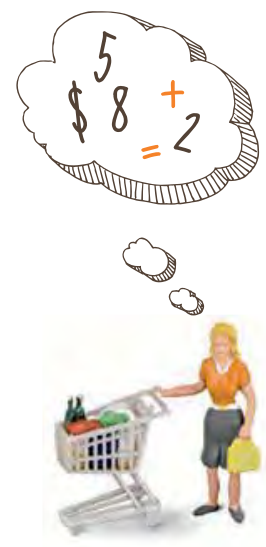

were aware of these and the majority simplified their calculations by choosing the most appropriate computation strategy for the specific endings. However, the most common approach of rounding up produced the least accuracy compared to the other computational approaches.

\section{Budget Shoppers Try Harder to be Accurate but Do Worse}

An exploratory field survey compared results from two different supermarkets in areas with differing poverty rates and average household incomes. Shoppers in the lower income area were more likely to keep track than those in the higher income area. They were also more likely to add the exact prices of all items and round prices to close denominations, whereas they were less likely to round prices down or up. These results suggest that shoppers in the lower income area try harder to be more accurate. In addition, the field survey indicated that respondents who tried to calculate the exact total price of the basket were unable to do so effectively and were the least accurate. The effect of "trying harder" was analyzed more closely in a laboratory setting. Half of the participant were given financial incentives depending on the accuracy of their estimation (high motivation condition). The participants in the low motivation condition received no cash incentive. The results confirmed that more motivated shoppers are more inclined to calculate the exact total basket price than less motivated shoppers (48.9\% versus $9.8 \%$ ). Again, despite their willingness to be accurate, the estimation performance of more motivated shoppers ended up being poorer. A second field survey underlined these findings and also revealed that the more shoppers underestimate their total basket price, the more they overspend relative to their budget (see Figure 1). When overspending happens, shoppers tend to hold the retailer responsible and feel dissatisfied with the store. On the other hand, when they pay less than expected, the benefit is primarily attributed to themselves and their level of store satisfaction remains unaffected.

\section{Helping Shoppers to be Accurate Is Favorable for Retailers and Consumers Alike}

Incorrect estimations have implications for not just consumer welfare but also retail performance. Shoppers who overestimate the total basket price are likely to 


\section{FULL ARTICLE}

spend less than they budgeted for - that is, they do not maximize their own utility under the budget constraints. Furthermore, they might reallocate the "saved" money to other budgets, which could entail a financial loss for the retailer. Shoppers who underestimate the total basket price are more likely to spend more than their grocery budget and to unintentionally reallocate more money to the "grocery account". This reallocation may trigger a chain of budget and spending decisions that could cause significant financial distress for budget shoppers and entail negative store satisfaction.

Therefore helping budget shoppers to be more accurate may represent a win-win solution, enhancing consumer welfare and retail performance. Educating shoppers about computational estimation strategies may enable them to become more informed shoppers. Alternatively new technologies could be offered, enabling them to accurately track their in-store spending (for example shopping cart scanners). Consumer welfare should improve, because shoppers can maximize their utility given their budget while minimizing the likelihood of spending more than planned and consequently store satisfaction remains undamaged.

\section{FIGURE 1:}

Underestimation of Basket Prices Entails Overspending

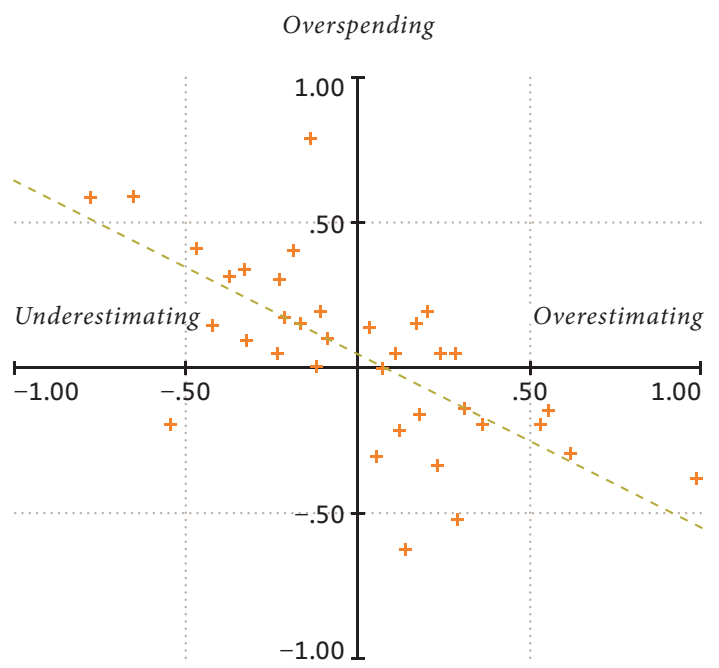

Underspending
Van Ittersum, Koert; Joost M. E. Pennings; Brian Wansink (2010),

"Trying Harder and Doing Worse: How Grocery Shoppers Track In-Store Spending", Journal of Marketing, Vol. 74 Issue 2, pp. $90-104$.

This summary of the article is published with the permission of the American Marketing Association.

\section{KEYWORDS:}

Shopping Behavior, Budget Shoppers, In-store Spending Behavior, Mental Computation, Basket Estimation, Retail Price Setting, Odd Prices

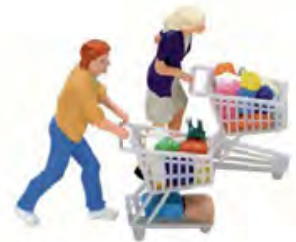

